\title{
Full-scale load tests of Pearl-Chain arches
}

Halding, Philip Skov; Hertz, Kristian Dahl; Schmidt, Jacob Wittrup; Kennedy, Bryan J.

\section{Published in:}

Engineering Structures

Link to article, DOI:

10.1016/j.engstruct.2016.10.022

Publication date:

2017

Document Version

Peer reviewed version

Link back to DTU Orbit

Citation (APA):

Halding, P. S., Hertz, K. D., Schmidt, J. W., \& Kennedy, B. J. (2017). Full-scale load tests of Pearl-Chain arches. Engineering Structures, 131, 101-114. https://doi.org/10.1016/j.engstruct.2016.10.022

\section{General rights}

Copyright and moral rights for the publications made accessible in the public portal are retained by the authors and/or other copyright owners and it is a condition of accessing publications that users recognise and abide by the legal requirements associated with these rights.

- Users may download and print one copy of any publication from the public portal for the purpose of private study or research.

- You may not further distribute the material or use it for any profit-making activity or commercial gain

- You may freely distribute the URL identifying the publication in the public portal

If you believe that this document breaches copyright please contact us providing details, and we will remove access to the work immediately and investigate your claim. 


\title{
Full-Scale Load Tests of Pearl-Chain Arches
}

\author{
Philip S. Halding ${ }^{\mathrm{a}}$, Kristian D. Hertz ${ }^{\mathrm{b}}$, Jacob W. Schmidt ${ }^{\mathrm{c}}$, Bryan J. Kennedy ${ }^{\mathrm{d}}$ \\ ${ }^{a}$ Technical University of Denmark, Department of Civil Engineering, building 118, DK-2800 Kgs. Lyngby, \\ Denmark, +45 4525 1811, phsh@byg.dtu.dk. \\ ${ }^{\mathrm{b}}$ Technical University of Denmark, Department of Civil Engineering, building 118, DK-2800 Kgs. Lyngby, \\ Denmark, +45 4525 1950, khz@byg.dtu.dk. \\ 'Technical University of Denmark, Department of Civil Engineering, building 118, DK-2800 Kgs. Lyngby, \\ Denmark, +45 4525 1773, jws@byg.dtu.dk. \\ dUniversity of Washington, Seattle, Washington, 98195, USA, bryanken@uw.edu.
}

\begin{abstract}
Specially designed, pre-fabricated, lightweight, concrete deck elements (SL-Decks) can be post tensioned together into an arch shape (Pearl-Chain arch). Individual arches can then be erected adjacent to one another in order to form a bridge span. Two Pearl-Chain arches, each with a span of $13 \mathrm{~m}$ and a rise of $1 \mathrm{~m}$, were erected onto a prepared test foundation. The aches were tested with load control by applying a gravity load to the $1 / 4$ point of the bridge span. Two tests were completed on the same specimen in order to determine the behavior of an arch bridge formed with SL-Decks. The first test investigated the system's elastic response (maximum load of $648 \mathrm{kN}$ ), and the second test demonstrated its collapse mechanism and ultimate capacity (maximum load of $970 \mathrm{kN})$.
\end{abstract}

Analytical calculations showed that the loaded 3/8 point of the span and the non-loaded $1 / 4$ points of the span were critical locations for the structure. Failure initiated at the 3/8 and 5/8 points. Plastic hinges were observed at a load near the fracture load, and different warning signs were seen at $84 \%$ to $94 \%$ of the fracture load. The ultimate, experimental load capacity was $14 \%$ higher than the calculated result (load of $849 \mathrm{kN}$ ), and the difference was mainly due to the assumed static system used in the calculations.

Measurements performed in Test 1 showed that the SL-Decks, which contained lightweight aggregate concrete blocks (LAC blocks) in the bottom of their cross sections, may have benefited from multiaxial compression effects. Furthermore, the pair of test arches were connected with so called Hammerhead joints in order to transfer forces from one arch to the other. The displacement data suggested that when a load was applied to a single arch, some proportion of that load was transferred to the adjacent arch.

Keywords: Full-Scale; Pearl-Chain Arches; Ultimate capacity; Arch bridge; Concrete; Post-tensioning; Structural behavior; Plastic hinges; Super-Light Deck elements; Testing to fracture. 


\section{Introduction}

This article presents and summarizes the results from two experimental tests of full-scale, Pearl-Chain, concrete arches. The test method was developed by considering previous analytical and experimental research of fullscale, traditionally constructed, reinforced concrete arches.

The difference between elastic and plastic ultimate strength calculations for statically indeterminate, concrete arches was addressed by Jain [1]. He studied circular, two-hinged arches subjected to a concentrated load at the $1 / 4$ point of the span. Beyond the elastic limit, when the concrete starts cracking, and the moment of inertia and material stiffnesses decrease, his proposed plastic calculation method gave a load carrying capacity 50\% to $100 \%$ larger than obtained elastically. The plastic response of a two-hinged arch begins when approaching the ultimate load. First, a plastic hinge forms below the load, due to the maximum, positive bending moment there. After further loading, another plastic hinge forms on the non-loaded side at the location of the largest negative bending moment. The second plastic hinge leads to collapse of the structure.

Jain dealt with a static system with a steel tension tie of a given stiffness, $E_{s}$, and area, $A_{2}$, to resist the horizontal force from the concrete arch of span, $\mathrm{L}$. The arch had stiffness, $E_{c}$, cross sectional area, $A_{1}$, and moment of inertia, I. Without taking areas of plastic deformations into account, the horizontal reaction force, $\mathrm{H}$, was:

$$
H_{\text {elastic }}=\frac{\int \mu \cdot y \cdot d s}{\int y^{2} d s+L\left(\frac{I}{A_{1}}+\frac{E_{c}}{E_{s}} \cdot \frac{I}{A_{2}}\right)}
$$

The parameter, $\mathrm{y}$, is the equation of the arch shape, and $\mu$ is the bending moment distribution of a similar beam (with no horizontal force). The small length, ds, is along the arch centerline axis. From having the arch reactions he calculated the thrust line, and found the normal force in the arch at any point on the span. The positive bending moment was much larger below the load compared to the negative moment in the non-loaded $1 / 4$ point. To achieve the optimal load carrying capacity, moment redistribution had to occur. That happened when the first plastic hinge was formed below the load where the moment was largest. At a certain length of the span below the point load, the concrete was in the plastic domain of the working curve. This additional angular deformation generated an increase in the horizontal reaction force and the line of thrust therefore became less inclined, compared to the purely elastic case. This change is illustrated in Figure 1.

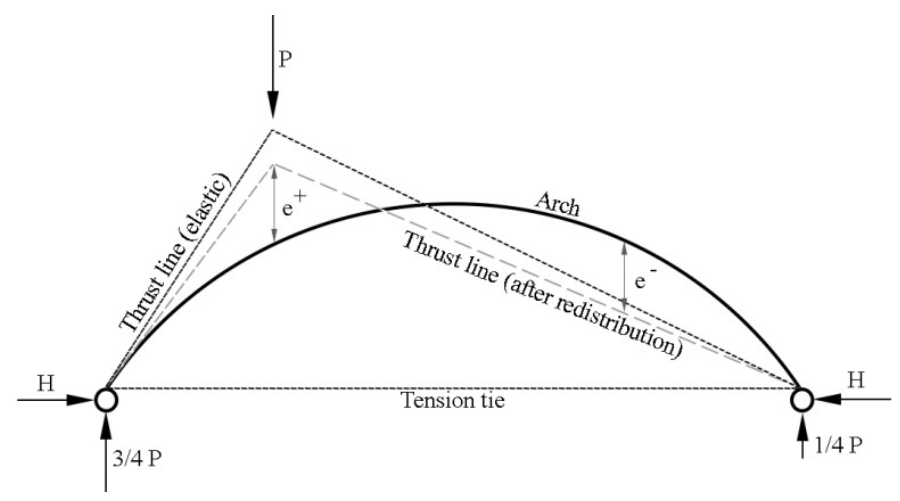

Figure 1: Thrust lines of arch loaded in $1 / 4$ point of span. 
In the figure the thrust line is shown for the elastic case and for the case with moment redistribution from plastic hinges. The optimal condition was a situation where the concrete could undergo enough angular deformation in the plastic hinge for the bending moment to reach the same level in the non-loaded $1 / 4$ point of the span as in the loaded $1 / 4$ point of the span. The eccentricity of the thrust line to the arch shape is shown in Figure 1 in the loaded-, $\mathrm{e}^{+}$, and the non-loaded side, $\mathrm{e}^{-}$. The horizontal reaction including plastic hinges was:

$$
H_{\text {pl_hinge }}=\frac{\int \mu \cdot y \cdot d s+E_{c} I \sum \Delta \phi \cdot y \cdot d s}{\int y^{2} d s+L\left(\frac{I}{A_{1}}+\frac{E_{c}}{E_{s}} \cdot \frac{I}{A_{2}}\right)}
$$

$E_{c} I \sum \Delta \phi \cdot y \cdot d s$ was extra outward movement of the arch ends due to the part of the arch span that had developed plastic strains. The potential extra outward movement was withstood as an increased $H$. $\Delta \phi$, is the extra angular deformation compared to the elastic case.

Jains proposed theory only included arches with the same cross section properties along the span. With that limitation the method was verified after several tests.

Marshall et al. [2] provided practical engineering guidelines based on experimental tests of three closedspandrel, reinforced concrete arches. Those arches had span lengths $12.8 \mathrm{~m}, 6.1 \mathrm{~m}$, and $11 \mathrm{~m}$. Their arches were cast into abutment walls, and soil-structure interaction was considered. Their $12.8 \mathrm{~m}$ span arch was tested during erection, during the compaction of the filling material, and later for a live load of $253 \mathrm{kN}$. The $6.1 \mathrm{~m}$ and the 11 $\mathrm{m}$ span arches were tested in a lab to fracture with symmetric point loads at the crown and close to the crown. Strain gauges were implemented in both tests, and were applied on the top and bottom of the arches at various positions along their spans. With this instrumentation, bending curvature (and therefore moment) could be calculated and correlated to the applied load for various points in the span. The $6.1 \mathrm{~m}$ span arch failed in a brittle, shear fracture mechanism, close to the fixed connection at the abutment support. Conversely, the $11 \mathrm{~m}$ span displayed a more ductile failure, with larger bending deformations before the ultimate load was applied.

Zhang et al. [3] used a similar method to determine the ultimate capacity of two existing, $20 \mathrm{~m}$ long, arch ribs. They measured strains at different span locations by instrumenting the top, bottom, and ribs of the arches. The vertical displacements were monitored at several span locations, and the abutments' horizontal settlement was also measured. The arches were loaded with point loads of same magnitude in both $1 / 4$ points and in the crown. A plastic hinge was observed in the 1/8 point of the span as the load increased and large cracks became visible before the ultimate load was applied. Their tested arches failed with a sudden shear fracture at the springings.

Another full-scale test was described by McGrath and Mastroianni [4]. An $8.5 \mathrm{~m}$ long, closed-spandrel arch bridge was loaded with a real, tandem-load truck. The bridge was further tested with a loading beam. That beam was connected to adjacent ground anchors, which were used to pull the beam downward onto the bridge. This loading simulated one axle of a heavy vehicle. Cracking was observed, but the bridge was not loaded to fracture. 


\subsection{Pearl-Chain Bridges}

Pearl-Chain (PC) Bridges are a relatively new arch bridge technology [5]. A PC-Bridge consists of several adjacent Pearl-Chain arches, with each arch assembled from a number of Super-Light (SL), pre-fabricated, concrete deck elements [6]. The SL-Decks are individually pre-stressed, mainly to resist forces from transport. The deck elements have a rectangular cross section, and are cast with a combination of normal concrete and a lightweight aggregate concrete (LAC). The normal concrete is used to form a top flange and ribs, while the LAC blocks stabilize the ribs and reduce the element's self-weight. In this paper, normal concrete is defined as regular concrete with compressive cylinder strength of $55 \mathrm{MPa}$. The SL-Decks are then assembled into a desired arch profile by means of Pearl-Chain reinforcement. Additional details on this reinforcing design were published by its inventor, Kristian Hertz [7]. Basically, a Pearl-Chain design uses a post-tensioning cable to fasten several SLDeck elements together. Post-tensioning ducts are draped within those elements so that the eventual, continuous duct follows the elevation profile of the complete structure. Furthermore, the ducts are situated so that the posttensioning cable will perpendicularly cross each joint along the arch. This prevents shear forces from developing across the joint interfaces between the deck elements when they are post-tensioned together and the arch is subjected to its self-weight.

A $6 \mathrm{~m}$ span, PC-Arch was previously tested [8]. The $6 \mathrm{~m}$ span arch was mainly produced to verify the assembly method of the three SL-Decks it consisted of. A pair of $13 \mathrm{~m}$ span arches were recently assembled (of 8 elements each), lifted, and positioned on a prepared foundation [9].

This paper presents experimental results on the behavior of the SL-Decks when used in an arch (Test 1), and the ultimate load capacity of the $13 \mathrm{~m}$ span, PC-Arches (Test 2). It is noted that a PC-Bridge would also include a filling material between the arches and road surface. A filler was not included with these arches, which is considered as a conservative design. Furthermore, it has to be emphasized that the test was performed on the two $13 \mathrm{~m}$ span arches only, and that the results therefore solely gives indications of a behavior. Figure 2 shows the two arches in their test position, after being assembled and erected.

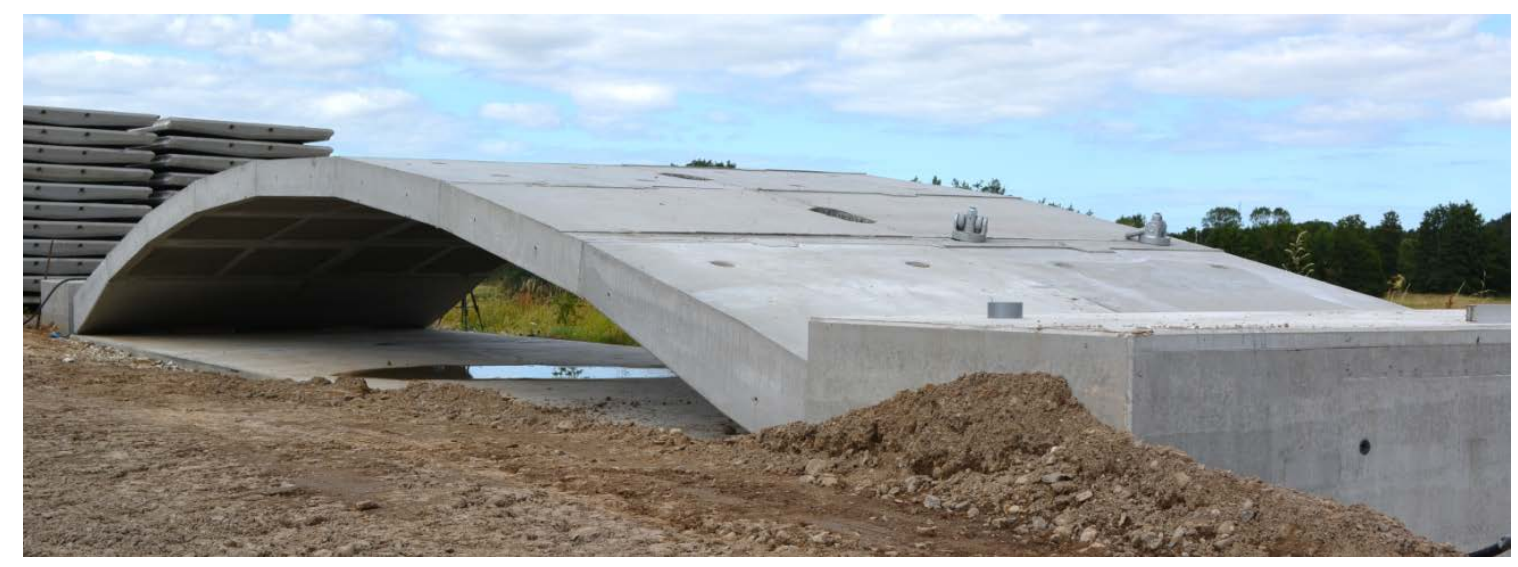

Figure 2: Two adjacent PC-Arches after assembly and lifting. 
The scope of the tests addressed in this paper was:

- Monitor deflections and strains during loading, and determine if forces are transferred between arches during loading.

- Investigate the behavior of the straight SL-Decks during loading, when used in an arch structure.

- Compare the ultimate load from testing with an analytical model.

- Find indication of clear warnings before the ultimate capacity is reached.

\section{Preparing the test}

The bridge assembly was tested two times. In Test 1, the arches were loaded with a total of 66 tonnes (648 kN) at the $1 / 4$ point of the span. Ten months later, they were re-tested in Test 2 to determine the load capacity, which was 98.8 tonnes $(970 \mathrm{kN})$. Both tests were scheduled for the same day, but due to problems with the loading crane, Test 2 was delayed.

\subsection{Geometry and materials}

Each arch consisted of eight elements (six SL-Decks and two abutment elements), which were post-tensioned together by 7C15 cables. All elements were made of the same concrete mix. The cables were first tensioned to $90 \%$ of the $0.1 \%$ proof stress of the steel $\left(f_{\mathrm{p} 0,1 \mathrm{k}}=1634 \mathrm{MPa}\right)$, and then grouted. The SL-Decks were approximately $1.60 \mathrm{~m}$ long, $1.75 \mathrm{~m}$ wide, and $220 \mathrm{~mm}$ in section height. This gave space for four LAC blocks across and two lengthwise in each deck element. The resulting area of the normal concrete in an arch cross section with LAC blocks was $0.196 \mathrm{~m}^{2}$. The SL-Decks had 10 pre-stressed mono strands in the bottom of the cross section with a concrete cover of $60 \mathrm{~mm}$, and 10Y20 bars (550 MPa mild steel) in the top of the cross section with concrete cover of $30 \mathrm{~mm}$. The material properties of the strands were the same as the previously mentioned post-tensioning cables. See Figure 3 for section cuts of the SL-Decks.

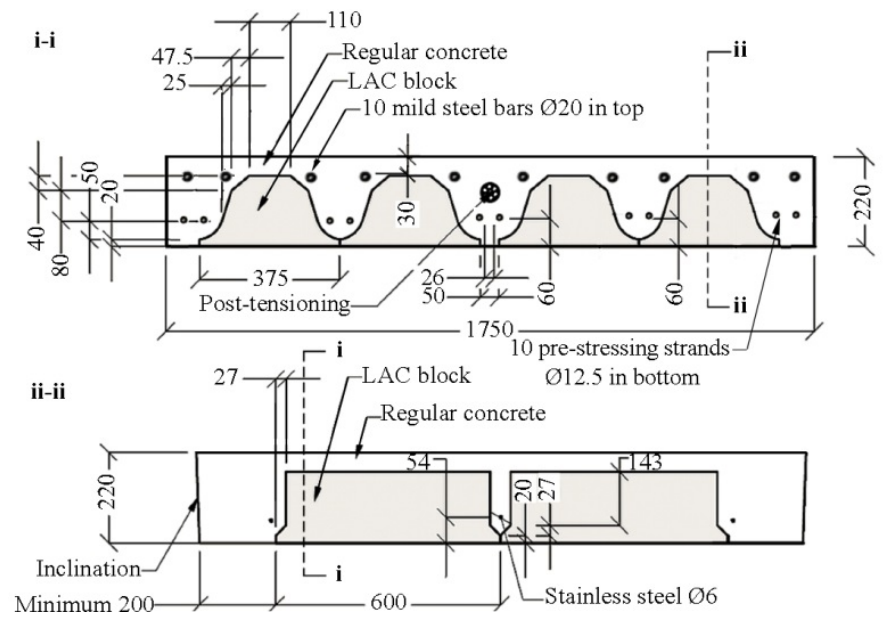

Figure 3: Detailed section cuts of SL-Deck type in the test arches. 
The normal concrete had a characteristic compressive cylinder strength of $\mathrm{f}_{\mathrm{ck}}=59 \mathrm{MPa}$ and a Young's modulus of $E_{\mathrm{cm}}=39 \mathrm{GPa}$. The concrete's theoretical strain at maximum stress was $\mathbf{e}_{\mathrm{c} 1}=0.26 \%$. Figure 4 is based on 28 day tests of the uniaxial compressive strength $\left(\mathrm{f}_{\mathrm{cm}}\right)$ combined with values of the Young's modulus $\left(\mathrm{E}_{\mathrm{cm}}\right)$ and strains ( $e_{c 1}$ and $\left.e_{c u 1}\right)$ calculated with the Eurocode 2 [10]. Cored specimens were tested after the collapse in Test 2 and gave approximately the same Young's modulus and strength.

The true curve would have been dependent on a variety of factors (e.g., mix design, aggregate size and type, and admixtures).

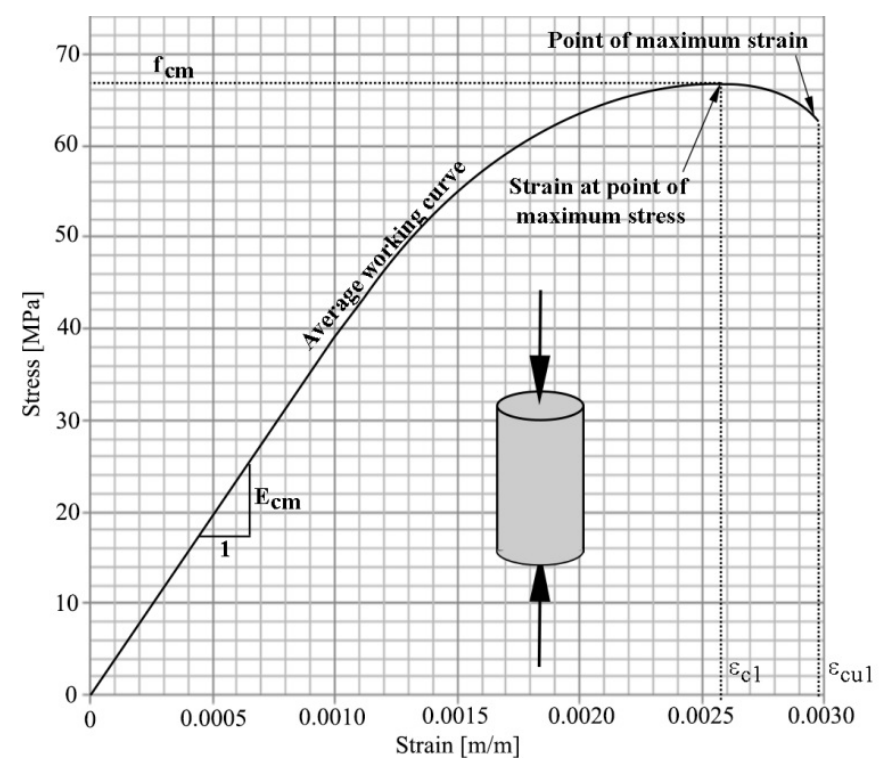

Figure 4: Theoretical working curve for the normal concrete in the SL-Decks.

Reinforced concrete plateaus were cast on top of the arches between the $1 / 8$ and 3/8 points of the span. These plateaus provided a level, horizontal surface for load application at the span's $1 / 4$ point. Both arches had their own, isolated plateau, each weighing an estimated $30 \mathrm{kN}$. Individual plateaus were chosen because one goal was to determine if an asymmetrical load would be shared between the arches. Therefore, a gap between the plateaus prevented the premature transfer of force at the load point. A layer of poly-ethylene was placed between each arch and plateau to reduce friction between the surfaces, and to hereby ensure that the load would act vertically.

The two arches were tied together with Hammerhead joints. These connections were designed to transfer forces from one arch to the other, and are shown in Figure 5. The connections are completed by first forming recesses in the sides of the SL-Deck elements. Once the arches are erected and aligned, a series of rebars are used to tie adjacent deck elements together. Finally, each recess is filled with mortar. The Hammerhead joint mortar had compressive cylinder strength of 12MPa, and a Young's modulus of $23 \mathrm{GPa}$. The rebar of a Hammerhead joint consists of Y12 (550 MPa mild steel) stirrups that protrude from the side of each SL-Deck, which are connected 
to a Y16 hoop with a Y16 steel bar. The connection detail is often used between deck elements in buildings, and is explained further in [9].

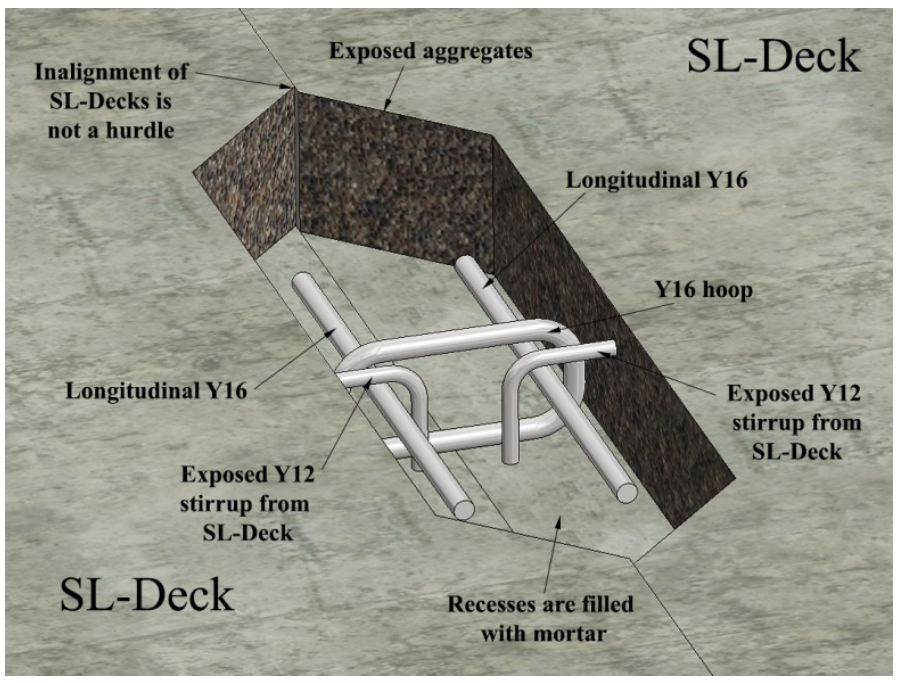

Figure 5: Explanation of transverse Hammerhead joint.

The mortar used in the joints between SL-Decks had a compressive strength greater than $80 \mathrm{MPa}$ at the time of the first test.

To avoid test result interference from horizontal settlement of the abutments, a post-tensioned abutment plate was cast as a foundation for the test arches. It consisted of concrete with characteristic compressive cylinder strength of $43 \mathrm{MPa}$, and a corresponding Young's modulus of $36 \mathrm{GPa}$. Three 7C15 post-tensioning cables were used to post-tension the abutment plate (similar to those in the arches). The distance between the ducts was 1.2 $\mathrm{m}$. The ends of the abutment plate were also heavily reinforced with mild steel. Figures 6 shows the test setup. 


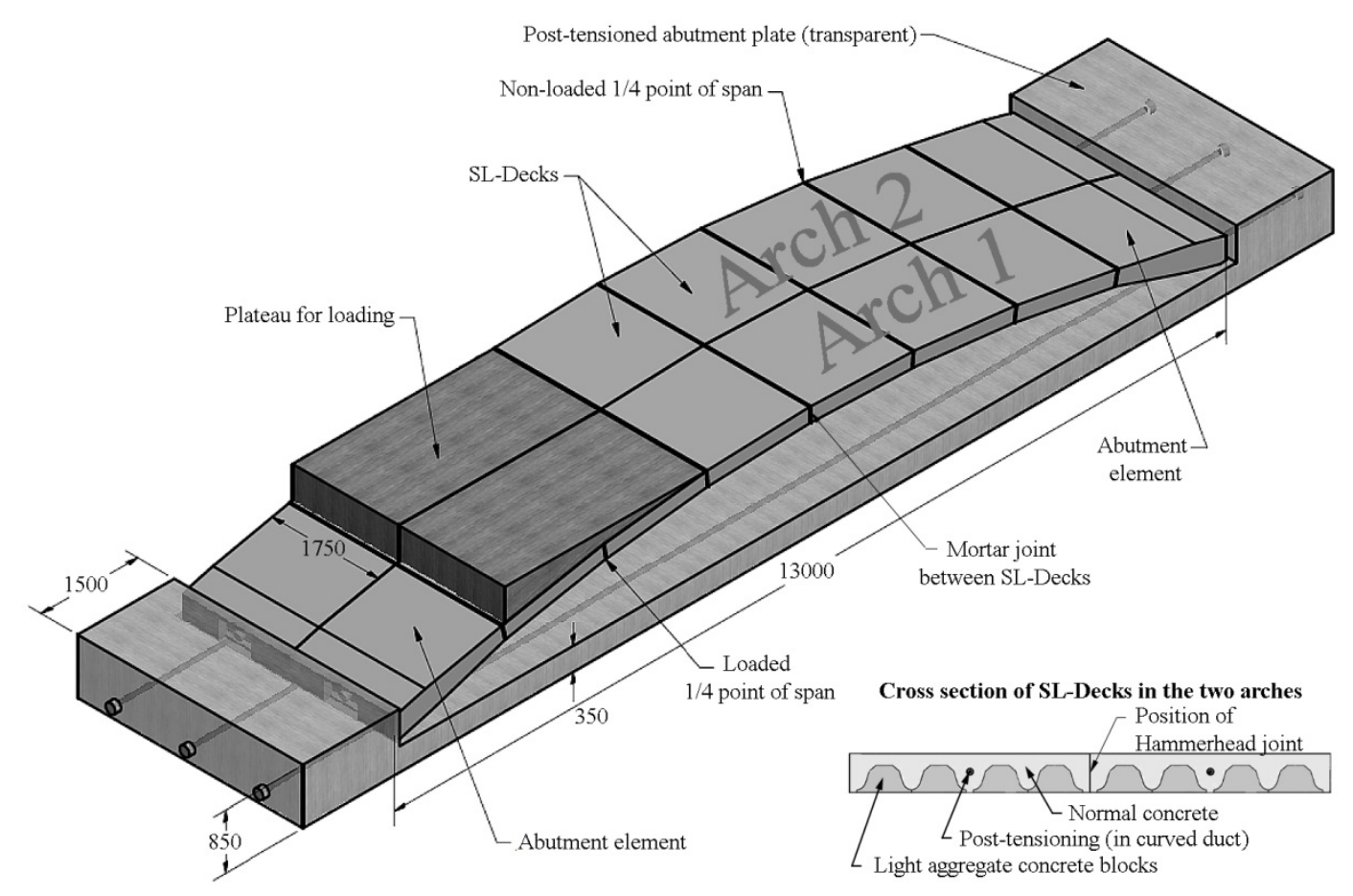

Figure 6: Test setup of two $13 \mathrm{~m}$ span PC-Arches placed on a post-tensioned abutment plate. All given dimensions are in mm.

Mortar was poured between the PC-Arches and the abutment plate. This mortar had similar properties as the one used in the Hammerhead joints. This was done to provide a smooth, continuous bearing surface for the lateral and vertical support reactions. Statically, it was expected that these joints - which lacked any sort of crossing reinforcement - would behave as hinges, so that the whole system would behave as a two-hinged arch.

\subsection{Measurement Methods}

\subsubsection{Arch Deflections}

Deflections were measured with three different methods: LVDT's, a leveling instrument, and a digital image correlation system.

Twelve linear variable differential transformers (LVDT's) were attached to different locations of the arches. Two of the LVDT's measured the horizontal settlement of the abutments, while the other 10 measured vertical deflections along the span length.

Vertical deflections were also measured by using a leveling instrument. The instrument was placed approximately $7 \mathrm{~m}$ from the side of "arch 1 ". Rulers where attached to the sides of both arches, and the deflection was measured through the leveling instrument when the load was applied. A total of 12 rulers were attached: 7 on "arch 1" and 5 on "arch 2". The leveling instrument was used both to verify the readings from the LVDT's, which were more accurate and precise, and to measure the deflections at locations where the LVDT's could not be applied. This was at the loading plateau, and at the $3 / 4$ joint, where detailed photographs were taken. 
Figure 7 shows the position and notation of all LVDT's and rulers. The measuring devices were positioned as close to the joints between SL-Decks as possible, and the joints were each given a location name: A, B, C, etc. The LVDT's named 1 and 2 measured the horizontal movement of the abutments at the end of "arch 1".

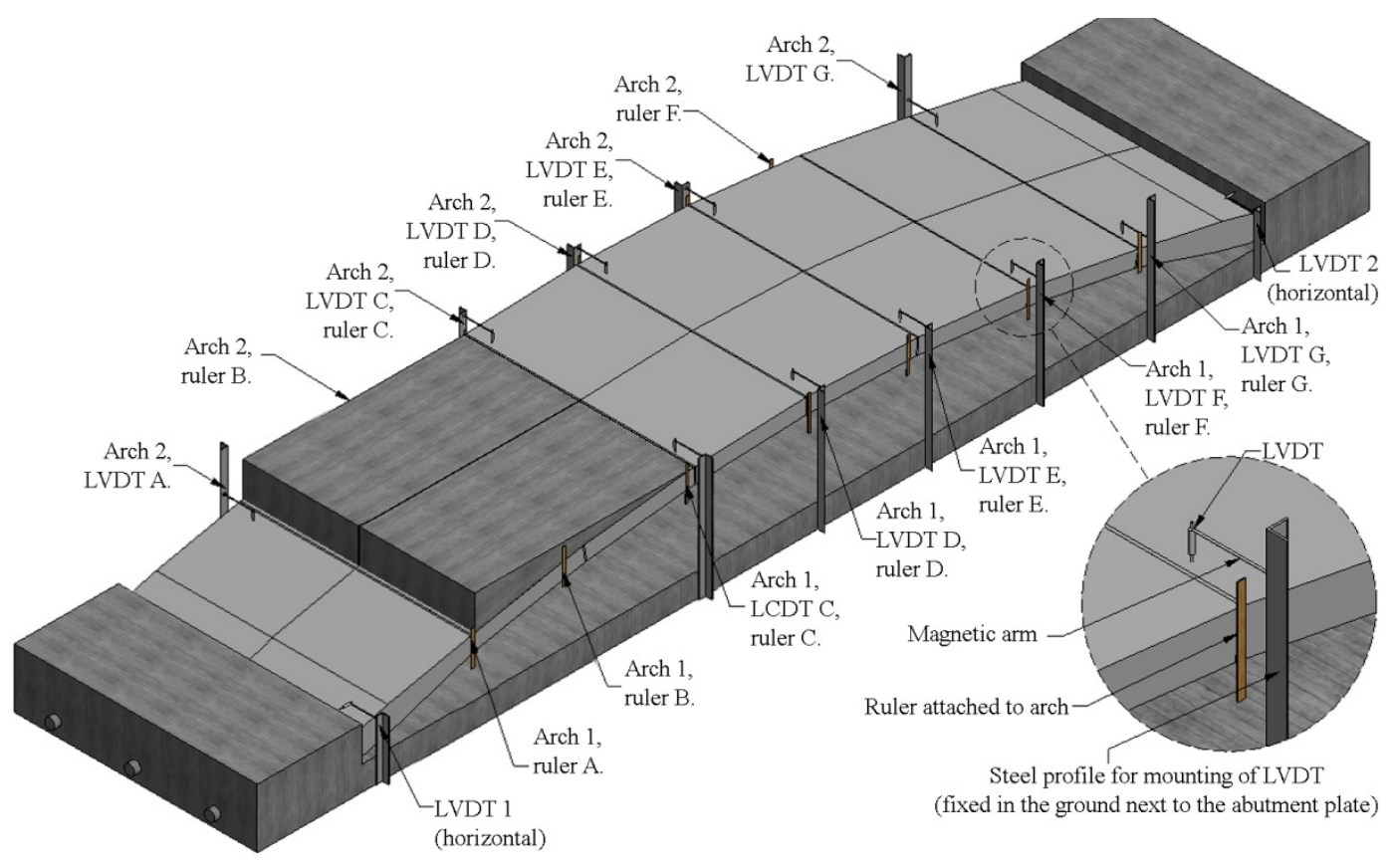

Figure 7: Position of all LVDT’s and rulers for measurement of deflections on “arch 1” and “arch 2”.

The third method relied on a digital image correlation system (DIC) system - ARAMIS.

\subsubsection{Strain Measurements}

Two methods were used to acquire strain measurements on the arches: ARAMIS and concrete strain gauges.

ARAMIS is a software package with digital image correlation technology [11]. After taking several pictures of a surface, the software can recognize and track facets of a defined size, and then compare the movement and deformation of these areas with a reference picture. The program can then generate several outputs, such as twodimensional strains and deformations of the photographed surface.

Photographs were taken on the side of the arches for processing in ARAMIS. The first two cameras were in location B (the loaded $1 / 4$ point of the span), two other cameras were in location $F$ (the non-loaded $1 / 4$ point of the span), and the last two cameras were placed at the joints to the abutment plate in both ends of "arch 2". All cameras were perpendicularly aligned to the arch surface, and several spot lights gave indirect light for best possible pictures. The 2d ARAMIS version was used. 
Strains were also obtained with concrete strain gauges, which were applied underneath "arch 2”. Eight, $50 \mathrm{~mm}$ long, concrete strain gauges were attached, which measured the strain in the longitudinal direction of the arch. They were positioned at location F, in two rows of four strain gauges, as shown in Figure 8. The first row was aligned with the middle of the SL-Deck and continued along its rib. The second row was placed along the side of the SL-Deck. A longitudinal spacing of $200 \mathrm{~mm}$ between gauges was used for each row, and all gauges were placed on the deck's normal concrete. In Figure 8, the dark rectangles are the bottoms of the LAC blocks. Line A is the position of a cross section in the SL-Deck through only normal concrete, and line B is the position of a cross section with both normal concrete and LAC blocks. The bottom of the non-loaded side was expected to be in compression during testing. Furthermore, it was expected to be one of two critical locations when approaching the ultimate load carrying capacity. The other important location was in the $1 / 4$ point of the span in the loaded side.

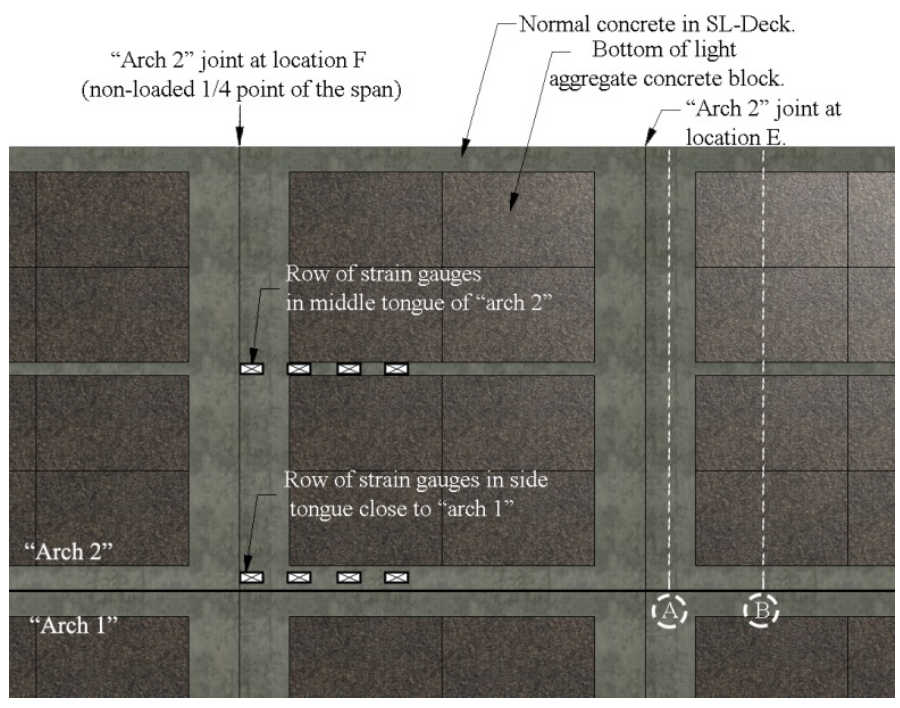

Figure 8: View from underneath “arch 2” at the joint at location F (for locations see Figure 7).

\subsection{Analytical calculations}

Before testing the arches, analytical calculations were performed in order to determine the initial strains at the most critical positions, and the expected load at fracture.

\subsubsection{Initial strains}

The self-weight (including the plateaus), pre-tensioning force within the individual SL-Decks, and the posttensioning force were included in this calculation. Figure 9 shows the sequence of initial loadings. State I is the strain distribution after pre-tensioning the SL-Deck. State II represents the post-tensioning of the arch and the application of its self-weight. States IIIA and IIIB represent the strain distributions at the loaded and non-loaded $1 / 4$ points, respectively, after applying the weight of the loading plateau. Those $1 / 4$ points were the theoretically most critical locations in the span assuming the load as being concentrated at the $1 / 4$ point. In reality the load on the plateaus was expected to be uniformly distributed from the $1 / 8$ to $3 / 8$ of the span in the first load steps. Later 
as the arch deflects, the load would be expected to concentrate in the regions of the $1 / 8$ of the span, and the $3 / 8$ of the span. This is due to the plateaus having a bending stiffness as well.
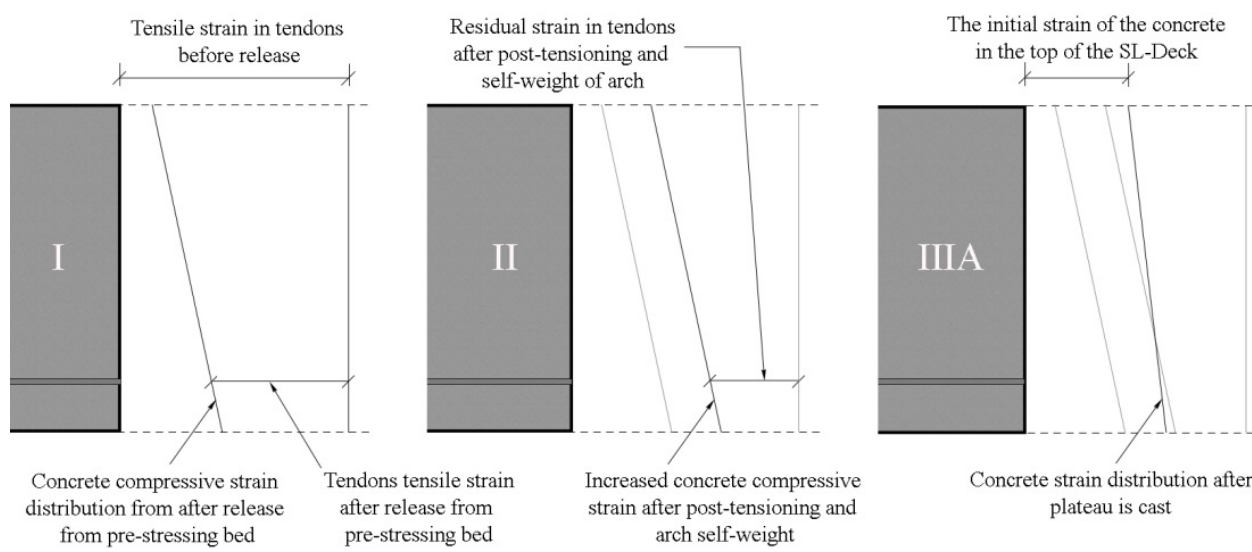

Strains near the loaded

$1 / 4$ point of the span before applying steel plates
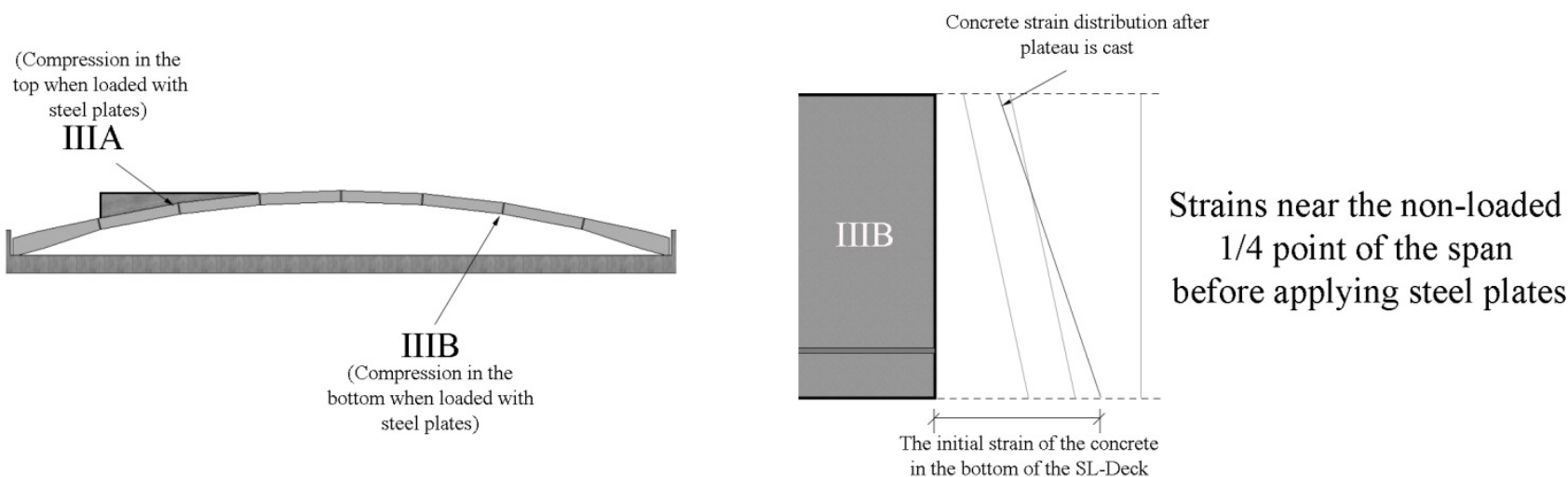

Figure 9: Initial elastic strain distributions in a SL-Deck in two positions before loading with steel blocks. The size of the strain distributions are not to scale.

The normal force in each arch from the initial contributions, less the expected initial loses, was $3251 \mathrm{kN}$. The calculated contributions to the normal force were: $166 \mathrm{kN}$ for the arch dead load, $1520 \mathrm{kN}$ for the eccentric prestressing strands, $1544 \mathrm{kN}$ for the central post-tensioning cable, and $107 \mathrm{kN}$ for the plateau dead load. The bending moment from the eccentric pre-tensioning was negative. In a cross section with LAC blocks it was -111 $\mathrm{kNm}$, and in a cross section of only normal concrete it was $-76 \mathrm{kNm}$. In the joints between SL-Decks there were no contributions from pre-tensioning.

The moment contribution from the dead load of the plateau was $43 \mathrm{kNm}$ close to the loaded $1 / 4$ point of the span, and $-28 \mathrm{kNm}$ close to the non-loaded $1 / 4$ point of the span. By Navier's formula we achieve the following elastic, compressive strains:

- In the bottom of the non-loaded side around location F: 
o With a full cross section of normal concrete the strain was $0.038 \%$.

o With a cross section including LAC blocks the strain was $0.10 \%$.

o In the joints between SL-Decks the strain was $0.0136 \%$.

- In the top of the loaded side around location B:

o With a full cross section of normal concrete the strain was $0.0142 \%$.

o With a cross section including LAC blocks the strain was $0.0073 \%$.

o In the joints between SL-Decks the strain was $0.0049 \%$.

The SL-Decks were chosen to have pre-tensioning in the bottom of the cross section only (cf. Figure 3), and this, along with the position and mass of the plateau, is the reason for the largest initial strain in the bottom of the non-loaded side.

\subsection{2. $\quad$ Expected load at fracture}

The load at fracture was at first calculated to be 56 tonnes $(550 \mathrm{kN})$ with the assumption of the full load being concentrated in the $1 / 4$ point of the span. As mentioned, the true static system is closer to two point loads in the $1 / 8$ point, and $3 / 8$ points of the span. This is the basis of the following simplified calculation:

By using Eq. 1 the horizontal reaction is determined. The steel tension tie properties are changed to fit the properties of the abutment plate in the test:

$$
H_{\text {elastic }}=\frac{\int \mu(x) \cdot y(x) \cdot d s}{\int y(x)^{2} d s+L\left(\frac{I_{\text {arch }}}{A_{\text {arch }}}+\frac{E_{\text {arch }}}{E_{\text {plate }}} \cdot \frac{I_{\text {arch }}}{A_{\text {plate }}}\right)}
$$

Then the bending moment, $\mathrm{M}(\mathrm{x})$, and normal force, $\mathrm{N}(\mathrm{x})$, is found. An example of the shape of the moment distributions is seen in Figure 10.

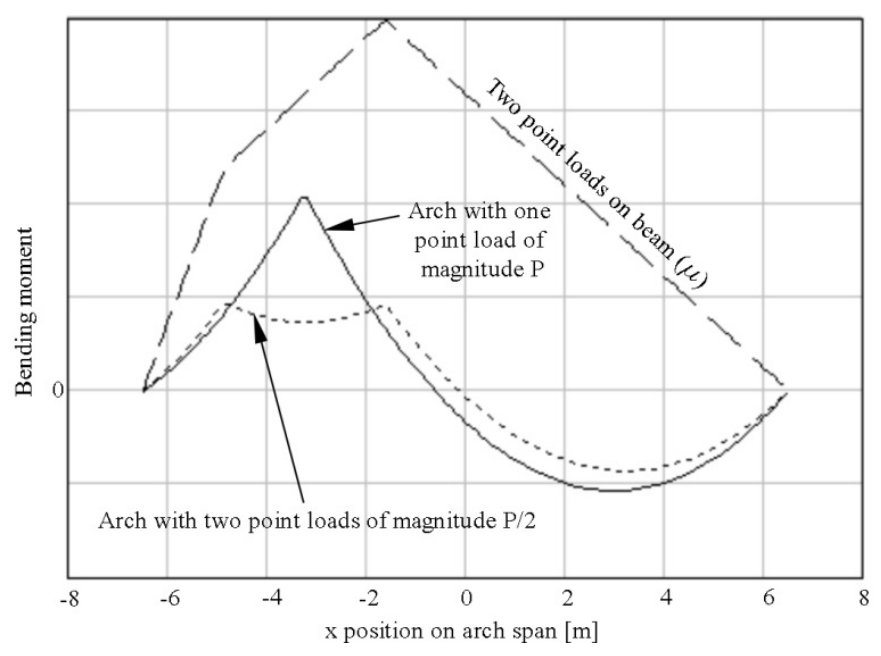

Figure 10: Bending moment in the arch from applied load. 
The $\mathrm{M}(\mathrm{x})$, and $\mathrm{N}(\mathrm{x})$ depend on the total load, $\mathrm{P}$. The bending moment capacity of the arch depends on the normal force. Using an iterative approach the direct load carrying capacity is found in terms of $\mathrm{P}$ :

1. Choose a $\mathrm{P}$, calculate $\mathrm{H}$, and find $\mathrm{M}(\mathrm{x})$, and $\mathrm{N}(\mathrm{x})$.

2. In the assumed most critical positions $(1 / 8,1 / 4$, and $3 / 8$ of the span in the loaded side, and the $1 / 4$ point of the span in the non-loaded side) calculate $\mathrm{N}$ and $\mathrm{M}$.

3. For the different magnitudes of $\mathrm{N}$ find the moment carrying capacity, $\mathrm{M}_{\mathrm{d}}$, of the three possible cross sections in the arch: A section with LAC blocks in the SL-Deck (Figure 3), a section with no LAC blocks in the SL-Deck, and a section through a joint between SL-Decks. In this step the value of $\mathrm{N}$ from the load, $\mathrm{P}$, is increased by the normal force from pre-stressing and dead load.

4. Compare the numerical value of $M$ and $M_{d}$ for all the positions on the arch span, and all types of cross sections in these positions. In this step the relevant initial bending moments are added to $\mathrm{M}$ found from the load, P. If $|M|<\left|M_{d}\right|$ in all possible combinations, then increase $\mathrm{P}$ and repeat the iteration.

By means of this purely elastic approach the load carrying capacity was found to be $\mathrm{P}=86.5$ tonnes. The capacity is found to be reached in the non-loaded side in the $1 / 4$ point of the span in a cross section with LAC blocks. At that point only little capacity is left in the loaded side in the 3/8 point of the span in the joint between SL-Decks. Therefore, the effect of possible plastic hinges is presumably insignificant.

\section{Test results}

The bridge assembly was tested with two separate phases, with different investigative objectives for each test. In Test 1 , deflections and strains were measured during loading to 66 tonnes (648 kN), when the test was stopped for safety reasons. This first test gave evidence for the transfer of forces through the Hammerhead joints, and permitted the study of the distribution of strains within an SL-Deck. Test 2, on the other hand, was conducted in order to determine the specimen's ultimate load capacity, and to observe its collapse mechanism. Figure 11 shows a photograph taken during Test 1.

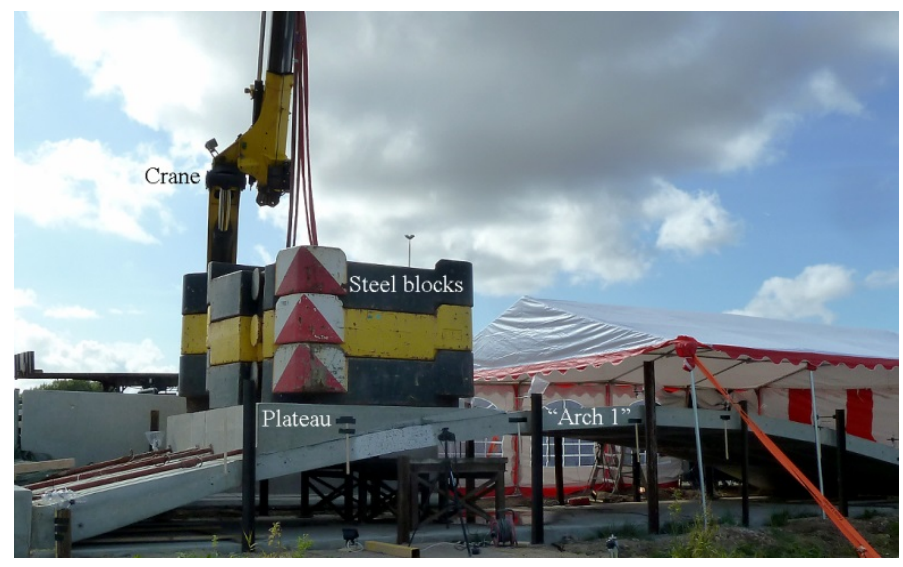

Figure 11: Test 1. Six steel blocks, each weighing 10 tonnes, were set on the plateaus on "arch 1" (near side in photograph) and "arch 2”. 
Test 1 was performed with the following procedure. The two arches were loaded with steel blocks, each weighing 10 tonnes $(98 \mathrm{kN})$. First "arch 1" was loaded with one block, and then "arch 2" was loaded with one block. This sequence repeated until three blocks were positioned on each arch, and then the arches were unloaded in reverse order. In Test 1, the maximum applied load at the $1 / 4$ point of the span was 66 tonnes (648 $\mathrm{kN}$ ), which included the mass of the plateaus. Test 2 was executed similarly, but with blocks weighing 6.4 and 10 tonnes. The specimen was loaded to failure of the arches, which occurred at a total load of 98.8 tonnes (970 $\mathrm{kN})$. Figure 12 shows the loading as function of time for Test 2.

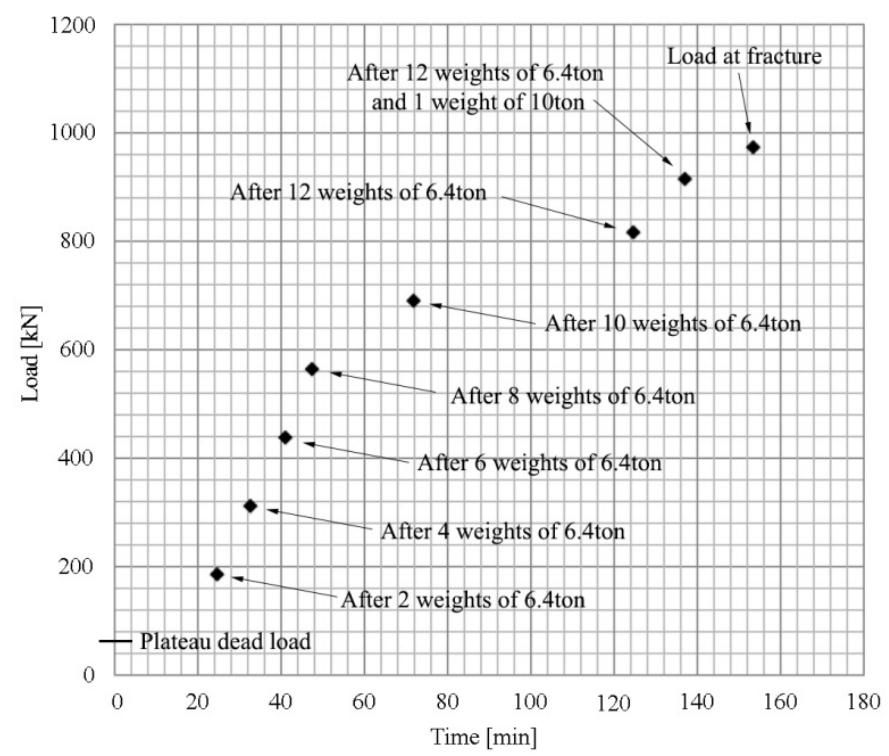

Figure 12: Loading sequence for Test 2.

\subsection{Test 1 - testing in the linear elastic range}

\subsubsection{Deflections and deformations}

The deflections measurements from the LVDT's were similar to those measured by the leveling instrument. Because of the LVDT's gave readings every five seconds, whereas the rulers were only read after every change in loading, only the LVDT data is presented here. In Figure 13, the deflection of "arch 1" is given, and in locations of no LVDT instruments, the deflections given by adjacent LVDT's have been supplemented with readings from the leveling instrument. For very small deflections, however, the leveling instrument lacked the resolution needed for useful results. During Test 1, the largest deflection on the loaded side was $15 \mathrm{~mm}$. In Test 2 , this value was $32 \mathrm{~mm}$ at the load level before fracture. 


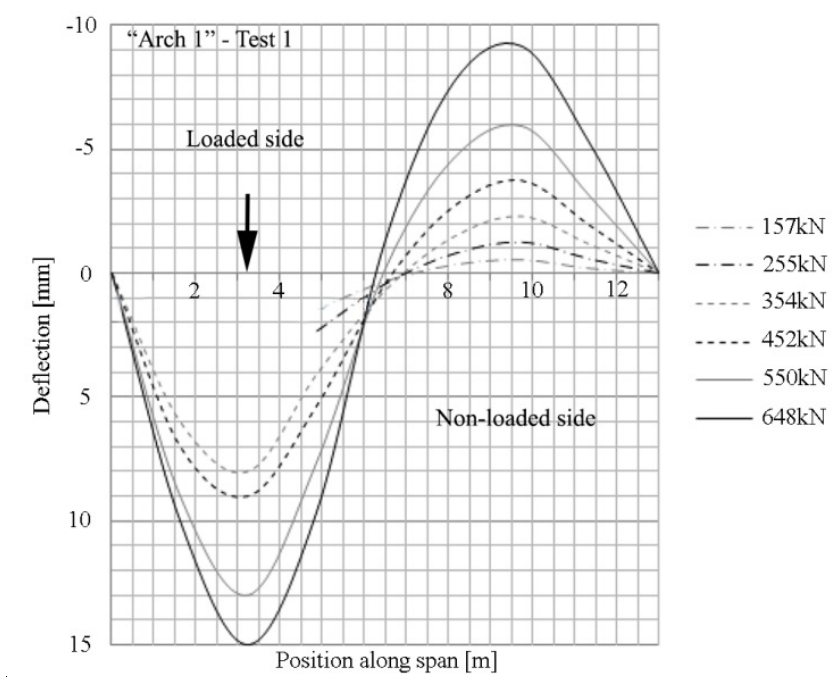

Figure 13: Deflection of "arch 1" for various total loads (accumulated from both arches) at the $1 / 4$ point of the span, not including selfweight.

Figure 14 shows the measured deflections of each arch as the loading progressed. The plot indicates that the Hammerhead joints transferred forces between the arches. However, there was some deviation between the deflections because of the unsymmetrical loading. The deflection in "arch 1" increased both when load was applied to "arch 1", but also when applied to "arch 2". The results from LVDT 1 and LVDT 2, measuring horizontal settlement of the abutments, showed insignificant deflections of less than $1 / 3$ of a mm. Therefore, all deflections in "arch 1" when applying load on "arch 2" must come from forces being transferred through the Hammerhead joints.

By comparing the arches' deflections at locations C, D, E, and G, it appears that the position closest to the loading plateau, had the largest difference in the defection between the two arches. In Figure 14, it is seen that at position C, "arch 1" deflected more than "arch 2" when the load was applied to "arch 1", and vice versa. This did not happen in the same way for positions D, E, and G. This trend was expected because the forces being transferred through the Hammerhead joints were likely largest at the location of applied load, but were smaller when moving away from that position. The Hammerhead joints for the test bridge were designed to transfer more than $100 \mathrm{kN}$ each. 


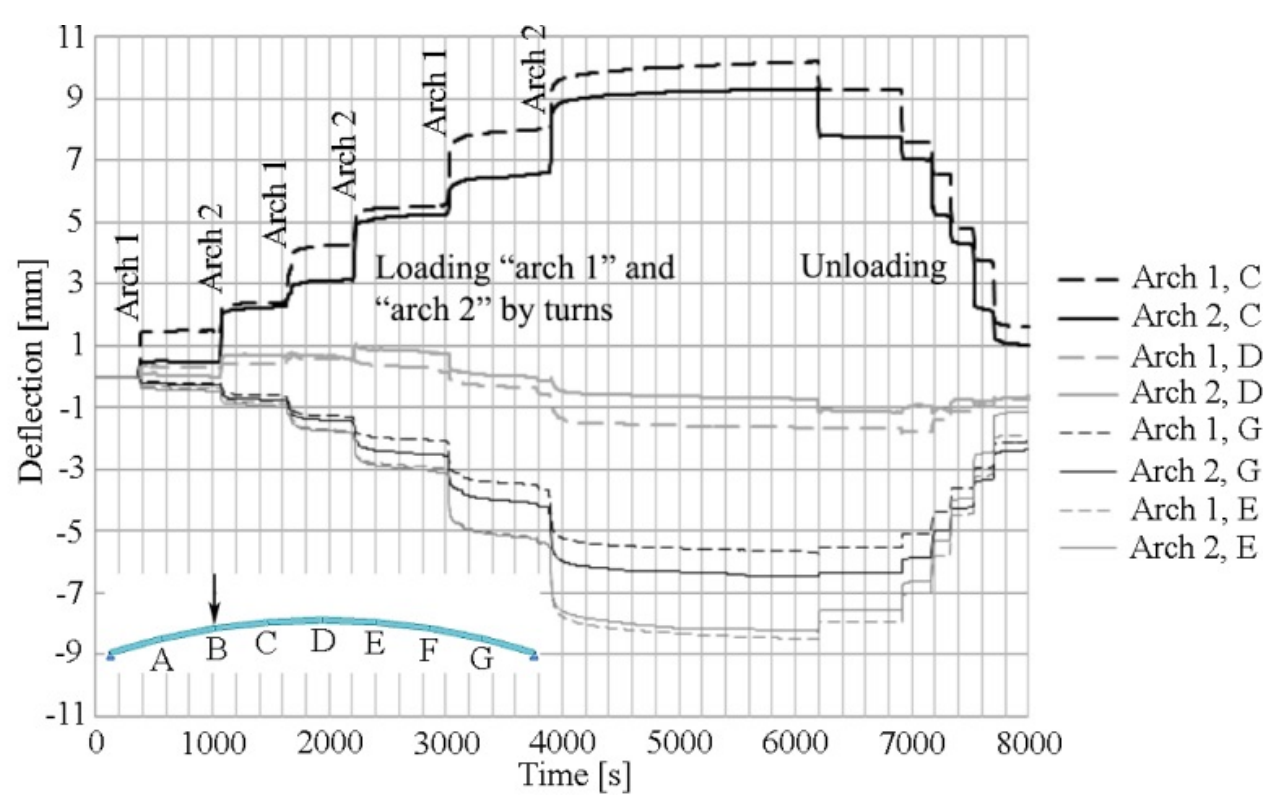

Figure 14: Test 1. Comparison of deflections of “arch 1" and “arch 2” at location C, D, E, and G (downwards is considered positive).

An ARAMIS system was used to monitor the arch deformation at the loaded and non-loaded $1 / 4$ points of the span (locations B and F, respectively). Vertical deformations found by ARAMIS corresponded well with the measurements from the LVDT's and the leveling instrument. Digital image correlation enables crack growth analysis by limiting the display output to strains above a certain value. Such analyses were complete for both the loaded and non-loaded $1 / 4$ points of the span. The non-loaded $1 / 4$ point (location F) did not show any cracking after applying the total of 66 tonnes, while some cracks appeared in the loaded $1 / 4$ point of the span (location B). Figure 15 shows the location of the DIC measurements (a), the vertical deflection contour plot at $648 \mathrm{kN}$ load (b), and the identified cracks at $648 \mathrm{kN}$ load (c). One crack developed between the plateau and arch, and another one from the arch into the plateau. Neither of those cracks affected the behavior of the arch itself. The plateau was not designed to transfer any significant shear to the arch - only direct vertical load. Therefore, some sliding between the two surfaces was expected. The separation was expected and verified the assumption of the static system being with two concentrated forces: one force at the $1 / 8$ of the span, and one at the 3/8 of the span. The plateaus likely had a large bending stiffness, and as the arch settled below the plateau, the load went from being uniformly distributed on the arch to being two point loads on the arch - one close to the $1 / 8$ point of the span, and one close to the $3 / 8$ point of the span. This was due to the arch deflecting more than the plateau, so that the contact surface was limited to the two areas close to the $1 / 8$ and $3 / 8$ points. 

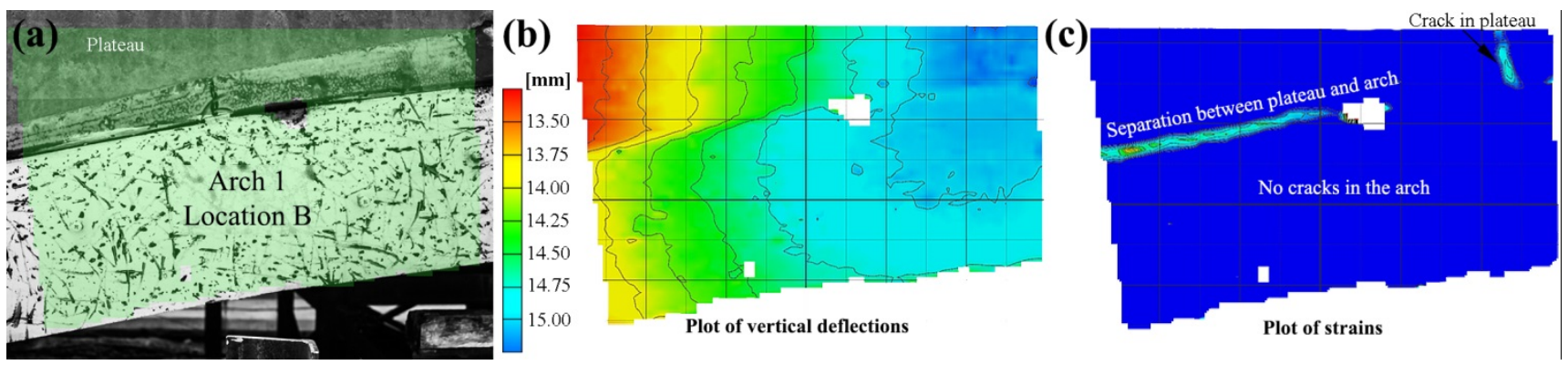

Figure 15: At $648 \mathrm{kN}$ load: ARAMIS output for the loaded quarter point at location B on the side of arch 1.

\subsubsection{Strains in SL-Decks}

At location F on "arch 2", concrete strain gauges were attached to the underside of the arch, see Figure 8 . The measured strains (in the longitudinal direction of the span) are shown in Figure 16. The vertical tick marks on the time axis indicate the time when each new $98 \mathrm{kN}$ load was applied.
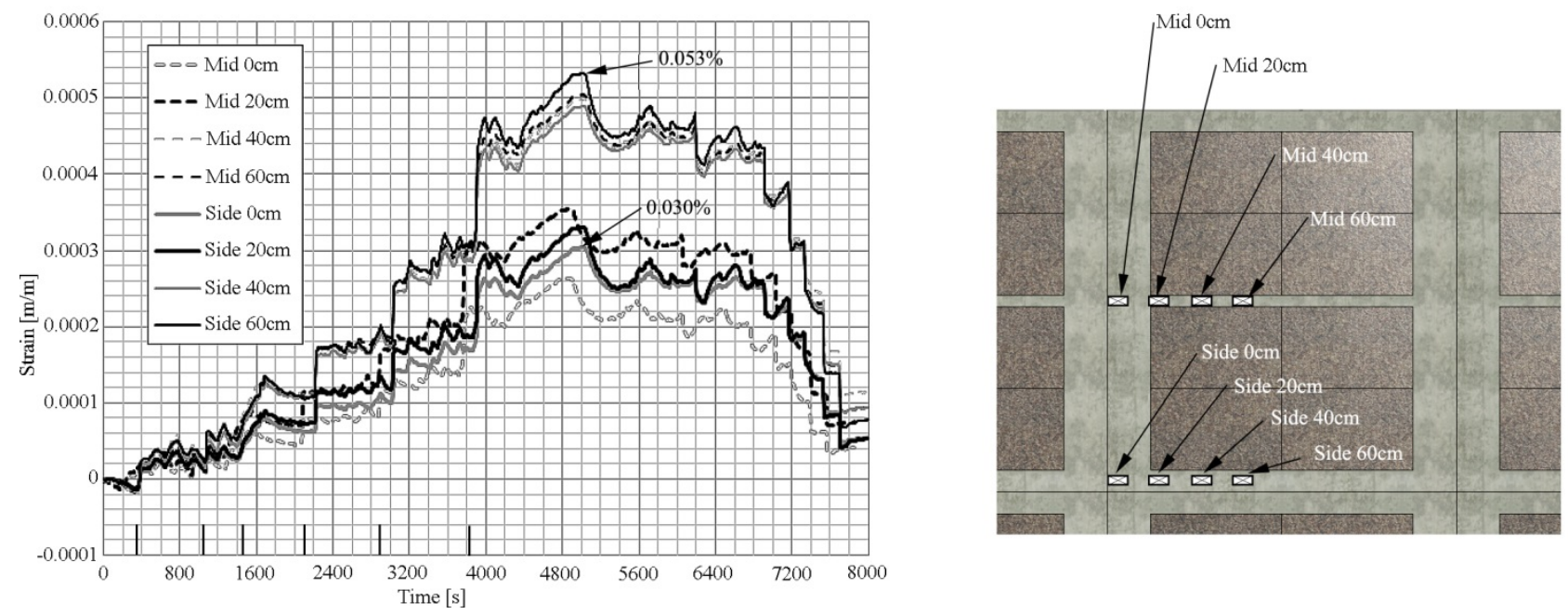

Figure 16: Strains from the eight strain gauges during Test 1 (not including initial strains).

The results show that the largest measured strains developed in the concrete ribs in a cross section of the SLDeck where the LAC blocks were located. This was expected, since the cross sectional area of the normal concrete was smaller in this zone compared to the zone with no LAC blocks at the ends of an SL-Deck. The thinnest rib was in the middle of the element, and the strains there were approximately $100 \%$ larger (at location "Mid $60 \mathrm{~cm}$ ") compared to the cross section without LAC blocks (at location "Mid $0 \mathrm{~cm}$ "). The strain gauge at "Mid $20 \mathrm{~cm}$ " was positioned at the transition between the cross sections with and without LAC blocks. Here, the 
magnitude of the strain was between the two extremes, since the normal force in the SL-Deck was being transferred from the large rectangular concrete section to the rib, which had a smaller cross sectional area.

The same trend occurred for the strain gauges at the side of the SL-Deck, although the concentration of the strains occurs a little further into the side rib. Where the "Mid $40 \mathrm{~cm}$ " and the "Mid $60 \mathrm{~cm}$ " measurements are almost similar, the difference between the "Side $40 \mathrm{~cm}$ ", and "Side $60 \mathrm{~cm}$ " measurements are up to $9 \%$. Also, the increase in strain from "Mid $0 \mathrm{~cm}$ " to "Mid $20 \mathrm{~cm}$ " was close to $40 \%$, while the increase from "Side $0 \mathrm{~cm}$ " to "Side $20 \mathrm{~cm}$ " was less than $9 \%$. The reason for the difference in how fast the strains concentrated was due to the ribs' relative sizes - the side rib was wider than the middle rib. Furthermore, a Hammerhead joint was located in proximity of the strain gauges "Side $40 \mathrm{~cm}$ " and "Side $60 \mathrm{~cm}$ ”. This could have had an effect on the results.

\subsection{Test 2 - Testing to failure}

The fracture load was 98.8 tonnes $(970 \mathrm{kN})$ which was $14 \%$ higher than the analytically calculated result of 86.5 tonnes (849 kN). Plastic hinges formed in both the loaded and non-loaded side of the arches during the last loading interval: from $94 \%$ to $100 \%$ of the fracture load. So they did not contribute to a $50 \%$ to $100 \%$ larger load capacity as explained by Jain [1], who stated that this occurs for arches with rectangular concrete cross sections and mild steel reinforcement.

Several different damage warnings were observed in the structure before the ultimate capacity was applied. Figure 17 shows three photographs at the moment of collapse: 1 . Plastic hinges forming on the loaded side, and then on the non-loaded side. 2. Loss of structural stability (a four hinged arch which is free to move) at the moment of fracture. 3. Final collapse. 


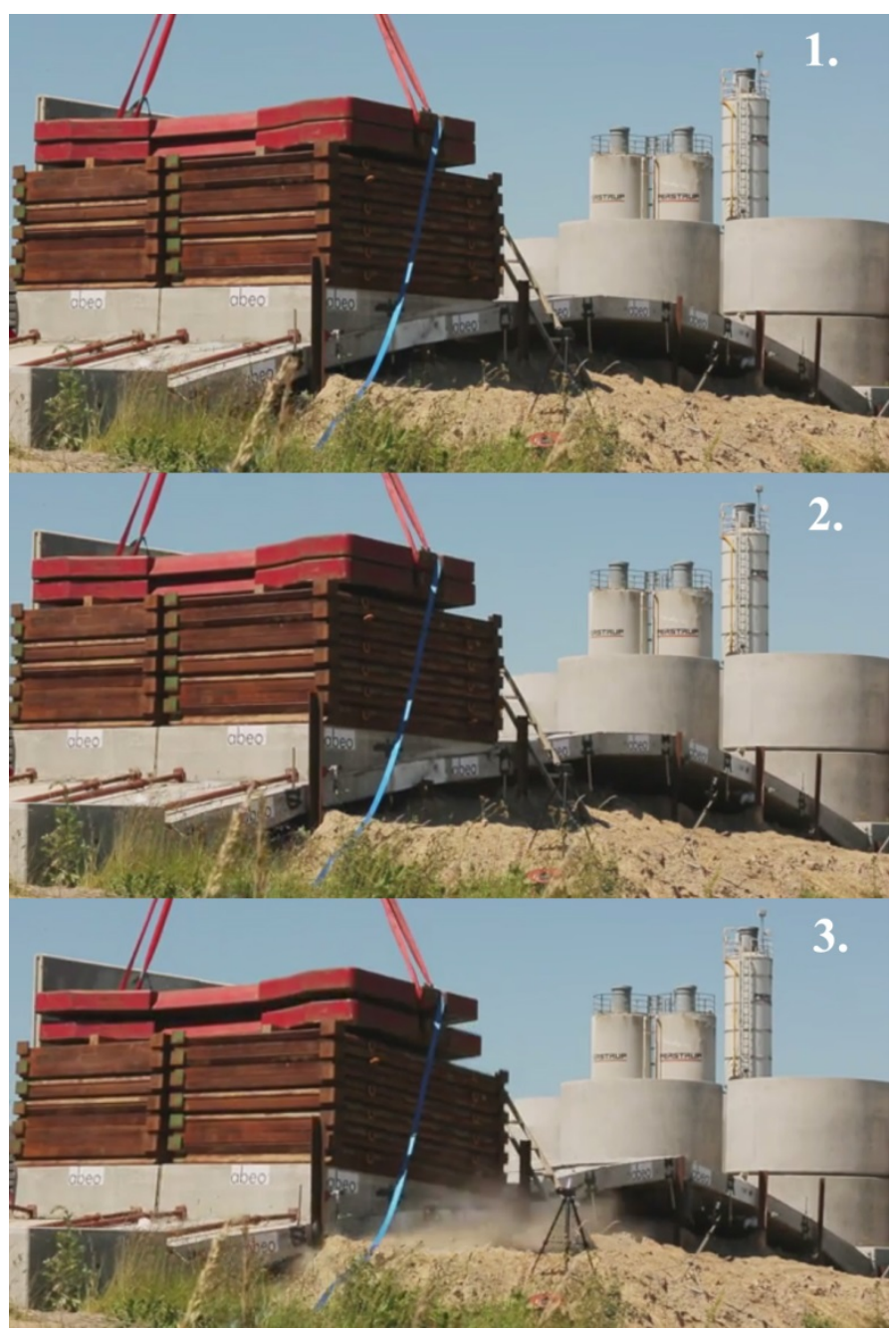

Figure 17: Sequence of observed failures preceding collapse.

\subsubsection{Test of theory}

The collapse occurred after two plastic hinges developed in the arch. The plastic hinges formed at the 3/8 and 5/8 points of the span. Theoretically, the most critical positions were found to be in the $3 / 8$ of the span in the loaded side, and at the $1 / 4$ point of the span in the non-loaded side, but only if the specimen behaved as a two-hinged arch. The cross sections where the hinges formed though were the same as predicted: In the joint in the loaded side, and in the SL-Deck with LAC blocks in the non-loaded side.

Hinge behavior was assumed at the interfaces between the foundation plate and the arch ends because reinforcement was not used to tie those elements together. At a low level of load $(<300 \mathrm{kN})$, however, the ARAMIS analysis showed limited rotation at the abutments, which suggested that the support connections were close to being fixed instead of hinged. At larger loads ( $>300 \mathrm{kN})$, clear hinge effect was observed, although it 
remained far from an ideal hinge with zero bending moment. A plot based on numerical calculations in the program Robot Structural Analysis [12] shows the difference in bending moment distributions, see Figure 18.

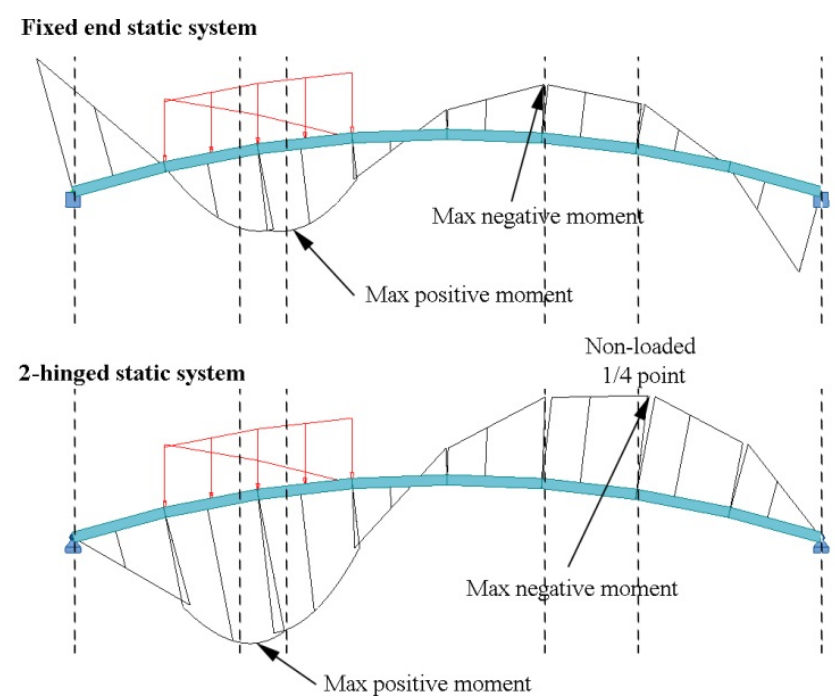

Figure 18: Bending moment distribution in fixed vs. 2-hinged arch of same geometry as the tested arches.

The true static system would have been somewhere between the two extremes. This may be the reason why the fracture occurred closer to the crown of the arch in the non-loaded side. Also, a small degree of fixation in the hinges may have reduced the bending moments and hereby give an increase in the load carrying capacity compared to the calculated value. In fact, when checking the load carrying capacity based on an arch with fixed ends, and a load corresponding to the fracture load from the test, there would still be a remaining moment capacity of $+102 \mathrm{kNm}$ and $-105 \mathrm{kNm}$ in the loaded and non-loaded side, respectively.

The expected failure mechanism was compressive crushing of the concrete in the bottom of the non-loaded side, or in the top of the cross section in the loaded side of the span. The actual failure was more complex due to the rotation in the points of the plastic hinges and the SL-Deck geometry in combination with the local stresses from the plateau used for loading. The following observations were made just before the ultimate capacity was reached:

1. A plastic hinge formed at the $3 / 8$ point of the span on the loaded side of the arch. The plastic hinge concentrated the stresses in that location, since the concrete crushed at the top and a transverse crack opened at the bottom. A longitudinal crack developed in the middle of the adjacent deck element, which was likely caused by a splitting mechanism that resulted from the concentrated normal load being transferred between the deck elements.

2. A plastic hinge formed in the $5 / 8$ point of the span, at which point the arch became an unstable structure (having four hinges). The 3/8 point was pushed downwards, and the 5/8 point was lifted upwards. This 
movement would have created a shear force, which would exacerbate the cracking at the $3 / 8$ point of the span.

3. The deflections and crack propagation occurred very quickly. As the plastic hinges moved upwards and downwards, the longitudinal crack lengthened in the mid-depth of the SL-Deck. The crack stayed in the middle of the cross section, probably because of the mild steel reinforcement and the pre-stressing strands in the top and bottom of the cross section.

Figure 19 depicts the observations leading to collapse.

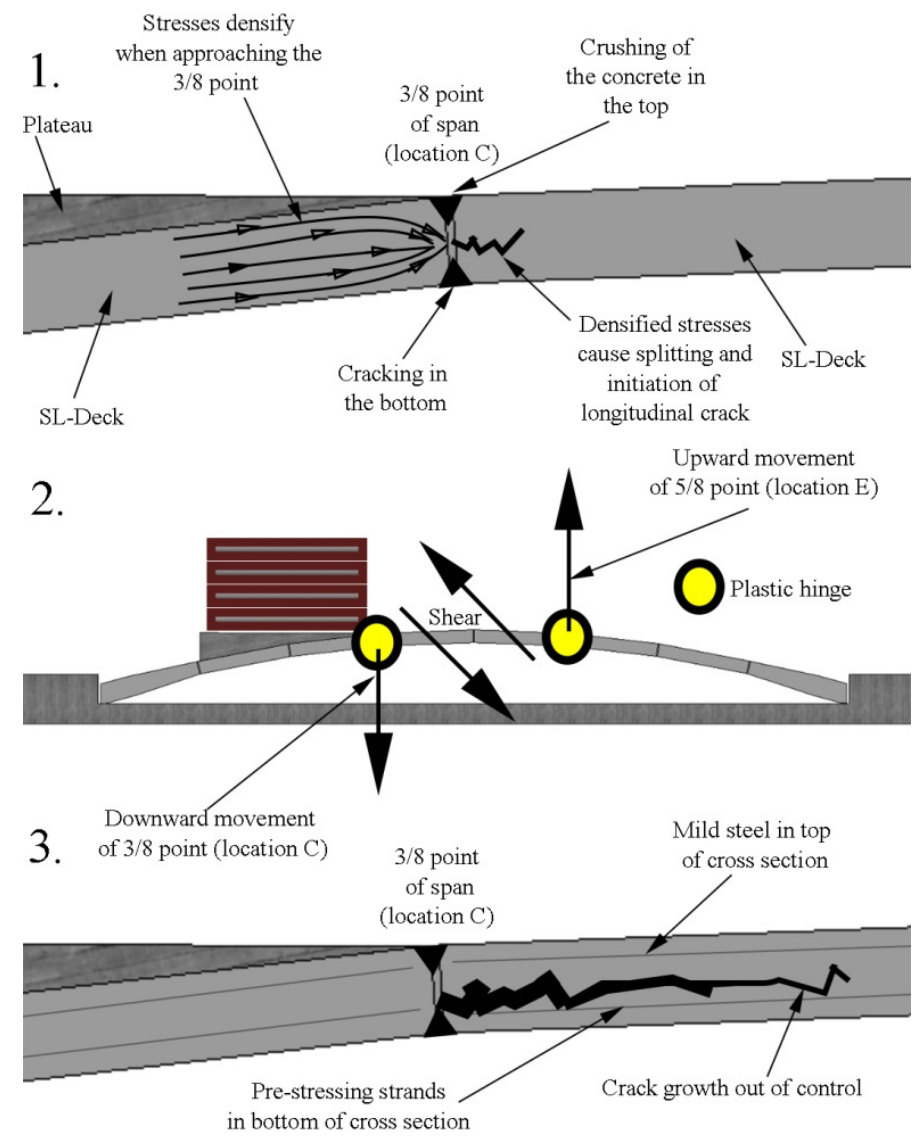

Figure 19: Sequence of events leading to final collapse.

Figure 20 shows photographs of the large longitudinal crack in the loaded side (3/8 point of span - location C), and crushing of concrete on the underside of the arch in the non-loaded side (5/8 point of span - location E). 


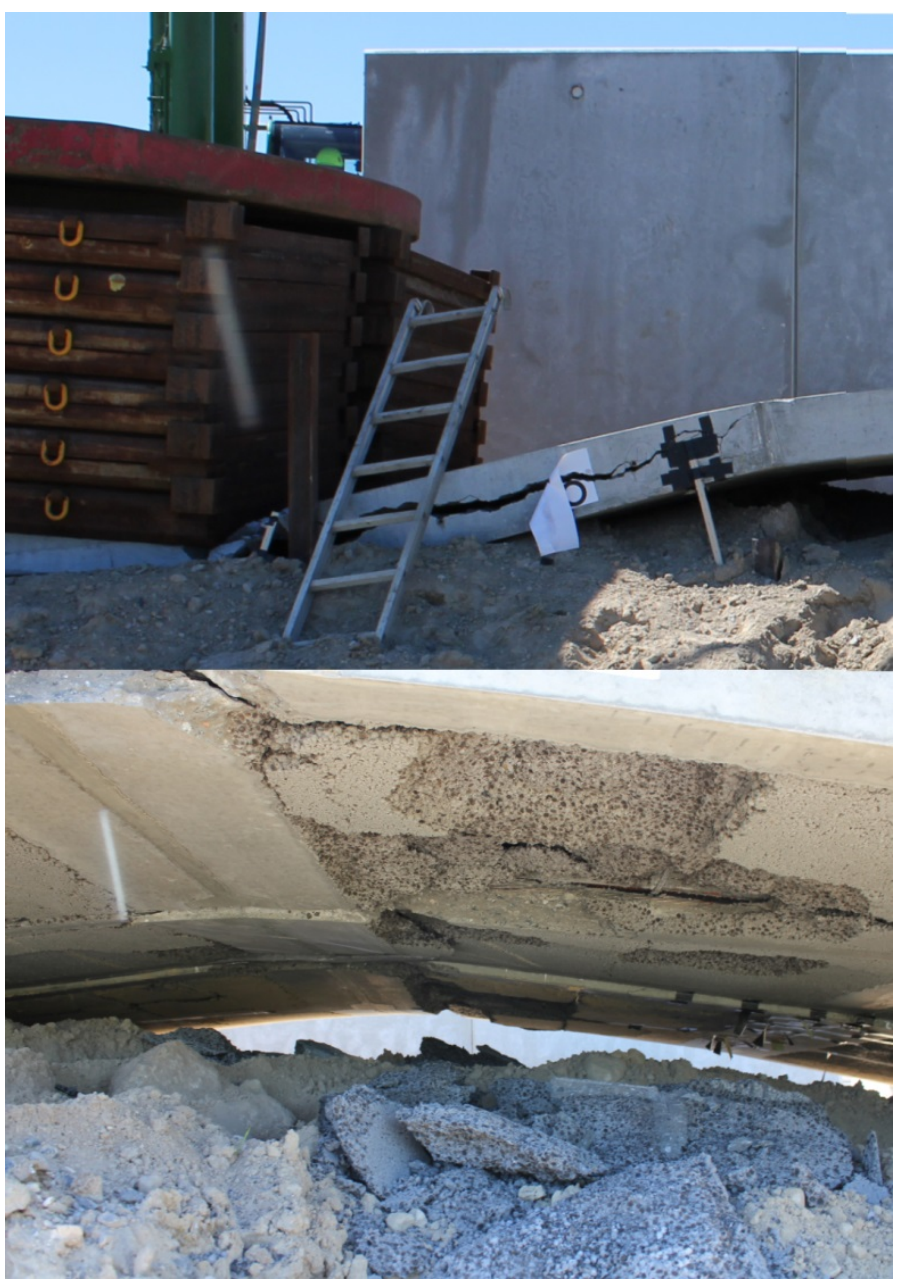

Figure 20: Photographs taken after collapse: longitudinal crack at 3/8 point (top) and crushed concrete at 5/8 point (bottom).

The PC-Arches seemed to form both plastic hinges nearly simultaneously. If this was true, then the same load resulted in concrete crushing strains at the $3 / 8$ and $5 / 8$ locations. With this damage observation, the results from the elastic analyses can be used to predict the load at failure.

Other reasons for the $14 \%$ difference between the calculated load capacity and the actual capacity are:

- Multiaxial stresses in the SL-Decks. We have shown how the stresses concentrate inside the SL-Deck and the confinement of the concrete may give a different working curve with a higher compressive strength compared to the one presented earlier.

- The strength of the LAC blocks has not been accounted for in the analytical calculations. The load bearing capacity is based on the normal concrete only.

\subsubsection{Warnings before fracture}


Highly pre-stressed construction members (arches in particular) are often assumed to have a brittle, unwarned fracture. However, the tested PC-Arches showed several warning signs before the collapse occurred. Figure 21 shows the change in system stiffness. On the main vertical axis the load is plotted as function of the deflections for all load levels in the loaded $1 / 4$ point - locations B - and the non-loaded $1 / 4$ point - location F. On the secondary vertical axis the corresponding stiffnesses are seen. There is clear system ductility since the stiffness decreases as the load and deflections increase. The figure is based on data from Test 2.

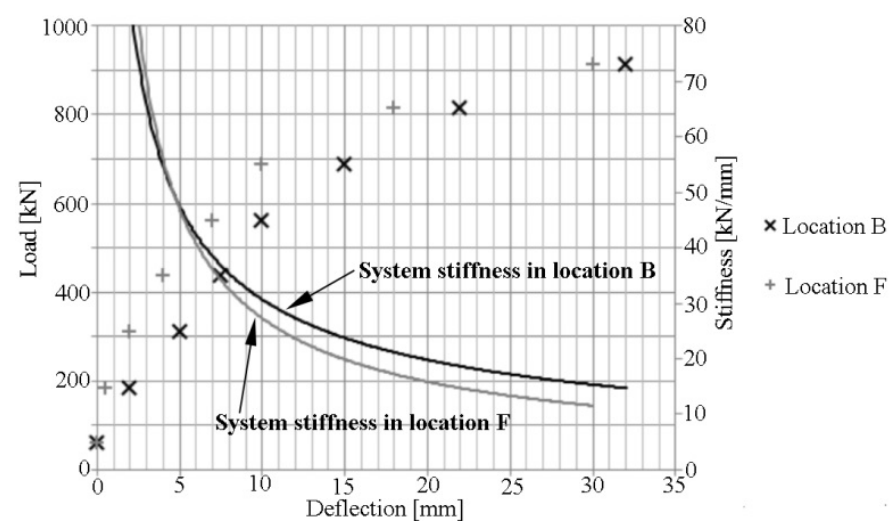

Figure 21: Deflections in location B and F at different loads, and corresponding system stiffness.

The first visible cracks were seen at the connection to the abutments where the hinge rotation took place. Figure 18 compared analyses of the two-hinged and fixed end static systems, and showed that the largest bending moment resulted at the abutments if fixed.

The cracks at the support "hinges" were initially observed at a load of approximately $300 \mathrm{kN}$, and grew as a result of additional loading. This means that visible cracks at the abutments were seen at a load level of $31 \%$ of the fracture load. At several locations, cracks were observed in the bottom of the loaded side of the arch at $84 \%$ to $94 \%$ of the fracture load. The non-loaded $1 / 4$ point of the span was closely monitored, but cracks were not observed there. However, cracking was observed in the top of the cross section at the 5/8 point of the span, where the plastic hinge developed before the collapse. Extensive concrete spalling was observed in the bottom of the arch close to that same location, also at $84 \%$ to $94 \%$ of the fracture load.

An interesting observation was that all cracking initiated at the connections between the SL-Decks and mortar joints, which seemed to be the weakest link.

\section{Conclusion}

The straight SL-Decks in PC-Arches worked as intended. The LAC blocks formed ribs in the SL-Decks which lead to a concentration of the stresses and multiaxial compression. The Hammerhead joints transferred forces between arches, and the two arches deflected similarly when loaded on one arch only. 
Analytical calculations predicted the critical locations to be the $3 / 8$ point of the span in the loaded side, and the $1 / 4$ point of the span in the non-loaded side. Two plastic hinges formed - one on the loaded side, and one on the non-loaded side of the span. However, those hinges formed at the $3 / 8$ and 5/8 points, as opposed to the predicted, $1 / 4$ point on the non-loaded side. This discrepancy could have resulted from the difference between the actual test setup and the ideal setup that would represent the theoretical static system. Most importantly, loading plateaus were used to transfer the gravity load to the arches. These plateaus had a significant bending stiffness and the bending deformation of the plateaus applied the load concentrated to the $1 / 8$ and $3 / 8$ points. This loading change affected the location of the plastic hinge on the unloaded side of the span.

The load at collapse was $970 \mathrm{kN}$ which was $14 \%$ higher than the calculated ultimate load of $849 \mathrm{kN}$ based on ideal abutment hinges. Possible reasons for the difference were: i) the abutment hinges had a rotational resistance, and must have decreased the bending moment and increased the capacity, ii) the strength in the SLDecks close to the ribs may have been higher due to multiaxial stresses, iii) the stabilizing effect of the LAC blocks was not considered.

Several damage warnings were observed before final collapse. First, the connections to the abutments started cracking at around 31\% $(300 \mathrm{kN})$ of the fracture load. Later, the arches cracked on the bottom of the loaded side, and concrete began spalling off from the bottom of the non-loaded side. This damage occurred at $84 \%$ to $94 \%$ of the fracture load. At this level of load, the largest measured deflection was $32 \mathrm{~mm}$ in the loaded $1 / 4$ point of the span. All cracks initiated at the interfacial, mortared joints between SL-Deck elements. Finally, large deformations occurred in the arches when the last $6 \%$ of the fracture load was applied.

The capacity calculations were correct. The tested fracture load was between the calculated capacity loads for a two-hinged (below), and a fixed end static system (above). Consequently, the tests demonstrated that the arches can be used to construct Pearl-Chain Bridges. A field implemented PC-Bridge would be a closed spandrel type of arch bridge. Such a bridge would include a filling material on top of the arches, in order to produce a level road surface. Additionally, this filling material would more evenly distribute traffic loads to the arches. After Test 1 was completed, the first PC-Bridge was successfully constructed in Denmark. That bridge had the same type of span and design as the test specimen, but used thicker SL-Deck elements.

The concept of PC-Bridges already includes the option of larger spans [5]. Furthermore, experimental tests of small scale models at the Technical University of Denmark showed that the design could be developed into a "sandwich arch" structure. If the backfilling material transfers shear between the arch and a concrete roadsurface-plate, the load bearing capacity could increase by a factor of up to 86. This interesting observation may be the basis of further research.

\section{Acknowledgements}

Many thanks for the help from the construction crew of Perstrup Betonindustri, the cooperation with the project manager Nicky Eide Viebæk, and the funding provided by Innovationsfonden. 


\section{References}

[1] Jain, O. P. (1960). Ultimate strength of reinforced concrete arches. American Concrete Institute -- Journal, 32(6), $697-713$.

[2] Marshall, J. D., Anderson, J. B., Meadows, R. L., \& Jensen, T. J. (2014). Full-Scale Testing of Three-Sided Precast Concrete Arch Sections. Journal of Bridge Engineering, 19(12), 04014051. doi:10.1061/(ASCE)BE.1943-5592.0000630

[3] Zhang, J., Li, C., Xu, F., \& Yu, X. (2007). Test and Analysis for Ultimate Load-Carrying Capacity of Existing Reinforced Concrete Arch Ribs. Journal of Bridge Engineering, 12(1), 4-12. doi:10.1061/(ASCE)1084-0702(2007)12:1(4)

[4] McGrath, T. J. (2002). Finite-element modeling of reinforced concrete arch under live load. Transportation Research Record, (1814), 203 - 210.

[5] Halding, P. S., Hertz, K. D., \& Schmidt, J. W. (2015). Precast Pearl-Chain concrete arch bridges. Engineering Structures, 103, 214-227. doi:10.1016/j.engstruct.2015.09.012

[6] Hertz, K., Castberg, A., \& Christensen, J. (2014). Super-light concrete decks for building floor slabs. Structural Concrete, 15(4), 522 - 529.

[7] Hertz, K. D. (2009). Super-light concrete with pearl-chains. Magazine of Concrete Research, 61(8), 655-663. doi:10.1680/macr.2008.61.8.655

[8] Hertz, K. D., \& Halding, P. S. (2014). Super-light pearl-chain arch vaults. Proceedings of the Iass-Slte 2014 Symposium.

[9] Halding, P. S., Hertz, K. D., Viebæk, N. E., \& Kennedy, B. (2015). Assembly and lifting of Pearl-Chain arches. Proceedings of Fib Symposium 2015.

[10] EN 1992-1-1 (2008), Design of concrete structures, $3^{\text {rd }}$ Ed.

[11] www.gom.com. Webpage of ARAMIS software. Last visited March 10, 2015.

[12] Autodesk Robot Structural Analysis Professional (2012), version 26.0.3.4375 (x64). 